\title{
Structure of local adaptation across the landscape: flowering time and fitness in Mexican maize (Zea mays L. subsp. mays) landraces
}

\author{
Kristin L. Mercer (1D · Hugo Perales
}

Received: 21 May 2018/Accepted: 11 September 2018/Published online: 25 October 2018

(C) The Author(s) 2018

\begin{abstract}
In crop centers of origin and diversity, often biotic and abiotic conditions vary across the landscape creating the possibility for local adaptation of crops, whereby local landraces perform better than non-local ones under local conditions. By studying patterns of local adaptation we can better understand the degree of adaptation of landraces, phenotypic mechanisms driving that adaptation, and the plastic responses of adapted populations to environmental change. Studying these basic processes in crop centers of origin and diversity improves basic understanding of adaptive evolution and provides insight for existing farming systems encountering climate change. Using maize landraces collected and reciprocally
\end{abstract}

Electronic supplementary material The online version of this article (https://doi.org/10.1007/s10722-018-0693-7) contains supplementary material, which is available to authorized users.

K. L. Mercer $(\varangle)$

Department of Horticulture and Crop Science, Ohio State University, Columbus, OH, USA

e-mail: mercer.97@osu.edu

K. L. Mercer

Department of Botany, University of British Columbia,

Vancouver, BC, Canada

H. Perales

Department of Agriculture, Society, and Environment, El Colegio de la Frontera Sur, San Cristóbal de Las Casas,

Chiapas, Mexico

e-mail: hperales@ecosur.mx transplanted in the field in two years along an elevational gradient in Chiapas, Mexico, we aimed to understand their degree of local adaptation, the distribution of adaptive diversity within elevations, and how landraces compared to improved varieties in their responses to environmental variation. We found some patterns consistent with local adaptation among the landraces, although the degree of adaptation differed across measures of fitness components and years. Flowering time variables showed more variability within elevations than total fitness estimates or fitness components did. Improved varieties, like low elevation landraces, were not well-adapted to conditions at higher elevations, although they did possess some beneficial traits. These data reaffirmed experimentally the local adaptation of landraces and their difficulty in reproducing under novel conditions, and indicated the importance of landraces for high productivity (especially in middle and high elevation systems).

Keywords Maize - Local adaptation - Landraces · Fitness $\cdot$ Flowering time $\cdot$ Anthesis-silking interval

\section{Introduction}

Patterns of local adaptation in plant populations have long been studied to better understand past 
evolutionary processes shaping adaptive variation. Factors that influence the rate of gene flow (e.g., mating systems) and the strength of selection (e.g., environmental distance) affect local adaptation since only when selection exceeds gene flow will populations be locally adapted (Lenormand 2002). Seventy percent of studies in a meta-analysis showed evidence of local adaptation (Leimu and Fischer 2008). Yet few studies explore local adaptation within agricultural landscapes, such as crop centers of diversity, where farmers and the environment play important roles in shaping crop diversity, especially landraces, or traditional varieties. Of particular interest are questions such as, how locally adapted are crops and how similarly adapted are crop populations grown in similar environments?

In the past decade, many have begun to study patterns of molecular genetic variation to elucidate signals of, and loci underlying, local adaptation (Tiffin and Ross-Ibarra 2014; Bragg et al. 2015). Investigations within agricultural landscapes and centers of crop diversity have helped clarify that biotic and abiotic factors can differentiate crop germplasm and that particular candidate gene loci may control that differentiation (Tiranti and Negri 2007; Hadado et al. 2010; Pyhajarvi et al. 2013; Samberg et al. 2013; Lasky et al. 2015; Takuno et al. 2015; Aguilar-Rangel et al. 2017; Kost et al. 2017). However, while uncovering the potential genetic basis of adaptation, such studies cannot help us discern the responses of actual plants to environmental variation, nor clarify their degree of local adaptation (e.g., Etterson 2004) or their range limits (e.g., Angert and Schemske 2005). Thus, working with quantitative genetic variation remains essential.

One classic way to study the local adaptation of plants is to perform reciprocal transplant experiments: take multiple populations that originate from different environments and plant them back into their own environment and into each other's (Kawecki and Ebert 2004). In natural systems, Clausen et al. (1941) clarified how these experiments, when performed across an environmental gradient, can discern not only genetic differentiation (as would a simple common garden experiment), but also local adaptation. We can identify local adaptation when local types (i.e., a landrace sourced from the same elevation as the garden in which it is grown) outperform non-local types in their local environments (Kawecki and Ebert
2004) - a particular form of interaction among genotypes and the environment $(\mathrm{G} \times \mathrm{E}$ interaction). Local adaptation is best assessed with total fitness, but other phenotypic characteristics may express similar patterns. Those phenotypes with an apparent relationship to fitness (i.e., where there may be opportunities for selection) may be acting as part of the mechanism of local adaptation. These putative mechanisms of adaptation may explain why local types do best (e.g., Etterson 2004; Angert and Schemske 2005). Finally, one benefit of this reciprocal-transplant approach is that some of the transplants (e.g., from cooler or wetter climes into warmer or drier ones) can mimic future environments with climate change and allow for assays of relevant plastic responses (Shaw and Etterson 2012).

Crop studies of adaptation and $\mathrm{G} \times \mathrm{E}$ interactions have been performed for the benefit of breeding efforts (Sanchez and Goodman 1992; Sánchez et al. 1993; Eagles and Lothrop 1994; Sanchez et al. 2000), but reciprocal transplant experiments have rarely been used to assess local adaptation (but see Mercer et al. 2008; Perales et al. 2005; Orozco-Ramírez et al. 2014). Our previous research using collections of lowland, midland, and highland landraces from throughout Chiapas and grown at two elevations (midland and highland), indicated patterns of asymmetrical local adaptation (Mercer et al. 2008). Highland landraces did worse growing in warmer climes than lowland and midland landraces did growing in cooler climes, largely due to the highland type having a lower probability of producing seed under midland conditions. Thus, identifying the nature of adaptation of landraces to their current environment will increase our understanding of how crops have evolved and may shed light on future potential for adaptation (Schmidt et al. 2012).

Adaptation can involve many kinds of traits, including stress tolerance or avoidance. Phenology, or the timing of important developmental stages, has been shown adaptively differentiate plant populations from different environments (Ducrocq et al. 2008). Phenology can evolve rapidly in response to environmental change, as seen with flowering time in both wild (Franks et al. 2007) and cultivated (Vigouroux et al. 2011) populations. For instance, pearl millet landraces from the Sahel evolved earlier flowering, accompanied by a change in allele frequency at the PHYC flowering time locus, over a 25-year period of 
drying in the region (Vigouroux et al. 2011). Flowering time traits may also prove to be important for local adaptation in our system, especially since shorter anthesis-silking intervals (ASI; the time between male and female flowering) in maize has been shown to boost productivity (Campbell et al. 2013).

In Mexico, the center of origin for maize (Matsuoka et al. 2002), about $75 \%$ of maize plants spring from farmer saved seed, most of which are from traditional landraces grown for subsistence production as openpollinated varieties (Aquino et al. 2001; Perales and Golicher 2014). Only an estimated 19-23\% of maize is commercial (Aquino et al. 2001; Luna et al. 2012), although some farmers do save (or recycle) seed of commercial cultivars as well (Bellon and Risopoulos 2001; Brush and Perales 2007; Bellon et al. 2018). By saving their seed yearly, landrace maize producers allow their landrace populations to evolve over time in response to their local environment and management. In Chiapas, the southernmost center of maize diversity in Mexico (Perales and Golicher 2014), landraces of maize predominate agricultural production. Chiapas also boasts a range of environmental conditions for maize production along its $3000 \mathrm{~m}$ change in elevation (Fig. 1) accompanied by changes in temperature and precipitation regimes.

This current research builds on previous work on local adaptation in maize landraces in Chiapas, Mexico in four ways. First, the collections were made on an elevational transect along which our common gardens were also established to better link environmental and genetic variation. Second, we sampled the populations in a stratified manner, rather than randomly, to discern the levels of phenotypic uniformity within an elevation among maize grown in different communities or by different farmers in a community. A number of studies have examined the structure of neutral molecular variation among regional maize landrace collections (e.g., Van Etten et al. 2008; Van Heerwaarden et al. 2009). None, as far as we know, has studied the structure of adaptive diversity across the landscape by inquiring into the variation within ecozones. Third, we included multiple commercial (i.e., improved) varieties among our genetic materials to explore their patterns of adaptation relative to landraces and to see where bred varieties may be more or less suited. Fourth, we performed the study over 2 years with disparate weather challenges to determine the degree to which the patterns of adaptation we observed were consistent.

Thus, for this study we focus on flowering traits and fitness components of 27 landrace populations collected from three elevations in Chiapas, Mexico, as well as five commercial varieties, reciprocally transplanted into the three collection elevations to discern patterns of adaptation. With this research, we ask:

1. Are the responses of fitness components and flowering traits of maize in local and non-local gardens indicative of local adaptation? To what degree are fitness components and flowering related?

2. How do commercial varieties perform relative to the landraces in the different gardens?

3. To what degree does maize from communities within an elevation and from populations within a community differ in responses to altered environments?

By answering these questions, we bring an ecological and evolutionary perspective to bear on the environmental responses of maize grown by farmers in southern Mexico, especially in this era of climate change.

\section{Methods}

\section{Genetic materials}

In early 2009, we collected seed lots of white maize landraces (hereafter, populations) from farmers in Chiapas, Mexico living along an elevational transect established from the hotter southern lowlands $(\sim 600$ $\mathrm{m}$ a.s.1.) adjacent to Guatemala to the cool mountains of the Central Highlands ( $2100 \mathrm{~m}$ a.s.1.) (Fig. 1). We only sampled farmers that affirmed they had used their population for at least 10 years without changing it. We sought three communities in each of three altitudinal ranges (within $50 \mathrm{~m}$ of our target elevations of $600 \mathrm{~m}$ a.s.l. = LL or lowland, $1550 \mathrm{~m}$ a.s.l. = ML or midland, and $2100 \mathrm{~m}$ a.s.l. = HL or highland) and collected 100 maize ears from each of three households in each community (see Supporting Information Table 1 for descriptions of each population). In two communities we did not obtain the three samples needed, in which case we collected an additional sample in a neighboring community. 


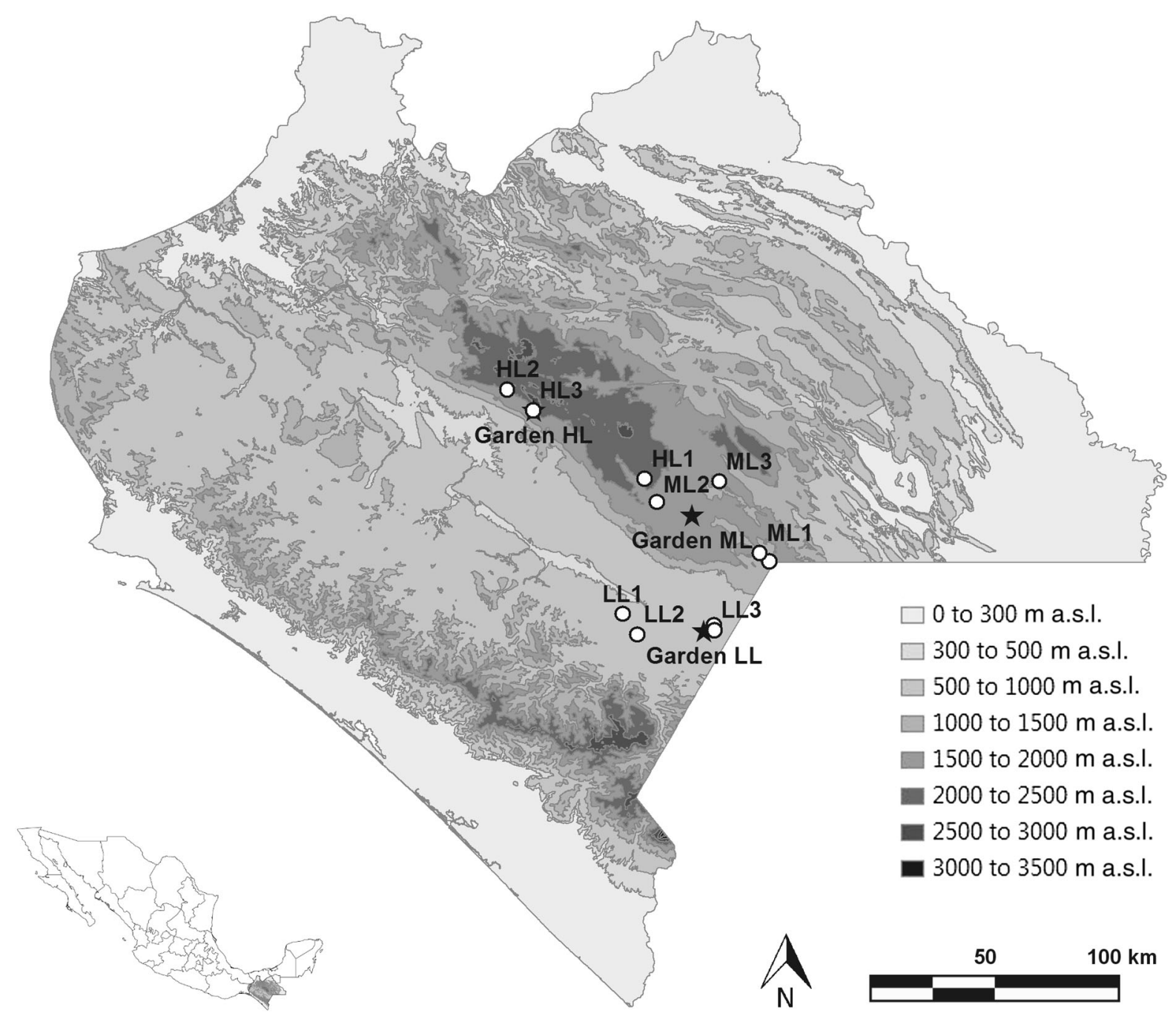

Fig. 1 Map of Mexico and Chiapas with elevational markings. Locations of communities where landrace maize was collected (dots; code as in Supporting Information Table 1) and of common gardens (stars) are marked. $L L$ lowland, $M L$ midland, $H L$ highland

While nearly 60 races of maize have been identified in Mexico (Sanchez et al. 2000; also see Anderson and Cutler 1942 and Wellhausen et al. 1952), only a handful of those can be found in any particular region. In our samples in Chiapas, all landrace populations from the lowland were of the Tuxpeño race; those from the midland were from the Comiteco race; six populations from the highlands were from Olotón race, while three (those from Comitán) were Olotillos (Brush and Perales 2007). These 27 populations constitute a spatially structured sample, allowing us to assess differences among elevations, as well as among communities within elevations, and populations within communities. Seed from all 100 ears of a given population were bulked to represent its diversity and stored in a cold room until planting. We also purchased seed from five commercial varieties sold in Chiapas and used primarily by lowland and sometimes midland farmers (see Supporting Information Table 1). No commercial varieties are available in the highlands.

Field studies

We rented land for field studies from local farmers, planted the crop within the normal time frame, and used local management practices. In 2011 and 2012, we planted reciprocal common garden field 
experiments in each of the three altitudinal levels: approximately $600 \mathrm{~m}$ a.s.l. for the lowland gardens (Frontera Comalapa: 2011, 594 m a.s.l.; 2012, 608 masl), approximately $1550 \mathrm{~m}$ a.s.l. for the midland gardens (La Independencia: $1531 \mathrm{~m}$ a.s.l.), and approximately $2100 \mathrm{~m}$ a.s.l. for the highland gardens (Teopisca: $2061 \mathrm{~m}$ s.a.l.) (Fig. 1). Using data gathered from the weather stations closest to our landrace collection and common garden locations, we can see that these elevations differ in their long term climatic conditions (see Supporting Information Table 2 summarizing data gathered for between 29 and 70 years from Clicom weather stations run by the Government of Mexico; Valenzuela and Cavazos 2017). In general, the highlands are about $8-10{ }^{\circ} \mathrm{C}$ cooler than the lowlands. Rainfall is more variable within elevation than temperature (there is also more error in its measurement), but there generally appears to be more rainfall at the lower elevations. Given the higher evaporation in the lowlands, highland locations tend to have greater moisture availability. The ratio of rainfall to evaporation (rainfall/evaporation) over the long term at our common garden sites is $1.16,1.61$, and 1.68 for lowland, midland, and highland locations, respectively. UV-B also is higher at higher elevations (data not shown). Thus, we expected our gardens to differ in multiple ways.

We saw obvious year to year variation at our field sites. In 2011 we had issues with establishment in the highland garden due to bird predation; in 2012 the midland garden experienced a severe drought. In both cases we replanted these gardens. In 2012 weather conditions were difficult in the lowland garden as well, but not enough to warrant replanting. Conditions were relatively optimal in the midland garden in 2011 and in the highland garden in 2012. Data collected during the 2011 field season near the garden locations indicated that the ratio of rainfall to evaporation was $1.88,1.76$, and 2.52 for lowland, midland, and highland gardens, respectively (Valenzuela and Cavazos 2017), a bit higher than average for all locations, especially the lowlands and highlands. In the 2012 field season, the ratio was lower than average in the lowland and especially the midland locations (0.96 and 0.91, respectively), but was higher than average in the highlands (2.4) (Valenzuela and Cavazos 2017). The fields were tilled prior to planting with a disk harrow and fertilized with $100 \mathrm{~kg} / \mathrm{ha}$ of fertilizer each of three times: at planting (with a 18:46:0 fertilizer), about
45 days after planting (with a 46:0:0 fertilizer), and just before tasseling (with a 46:0:0 fertilizer) [where all ratios represent percentages of nitrogen $(\mathrm{N})$ : phosphate $\left(\mathrm{P}_{2} \mathrm{O}_{5}\right)$ : potash $\left(\mathrm{K}_{2} \mathrm{O}\right)$ applied]. Weed control, done on an as-needed basis at each of these three time points, included pre-plant herbicide to control grasses, and herbicides or hand-weeding during the season.

In each garden in each year, we established a randomized complete block design with four blocks. One plot of each collected landrace population and commercial variety was randomized in each block. Plots measured $4 \mathrm{~m} \times 6 \mathrm{~m}$ with four rows of 7 matas (hills or planting positions) at $80 \mathrm{~cm}$ centers, into which three seeds were planted; we then thinned each mata to a maximum of two plants. Within each plot, we collected data from one focal plant from each of the ten central matas (excluding edge matas), resulting in ten observations (subsamples) of a given population per plot and four plots. Thus 40 observations of each population were made per location each year, except where there was missing data. Although data was collected on individual plants, plot means were used for many analyses, so $\mathrm{n}=4$ (see below in "Data analysis" section).

The plant designated as focal in any given mata was chosen by alternating back and forth (between leftmost or rightmost plant) along the row to reduce bias, while maintaining ease of data collection. Flowering times (male and female) were assessed daily during the flowering period; anthesis-silking interval (ASI) was calculated as female flowering (or silking) date minus the male flowering (or tasseling) date. The proportion of plants that never flowered, only tasseled, only silked, and tasseled and silked were calculated as direct counts since high frequencies of zeros precluded convergence of binomial analyses. Data on plants that only silked and on those that tasseled and silked are not presented, since those that only silked were rare and those that tasseled and silked largely reproduced (i.e., these data are similar to the data on survival to reproduction) presented here.

At harvest, all ears from all reproducing focal plants were collected and dried. All plants that produced at least one seed were said to have survived to reproduce. Primary and, where present, secondary ears were each weighed individually and the seeds and cob of the primary ear were weighed separately. Up to 100 randomly chosen seeds per primary ear were also weighed to estimate weight per seed and total seed 
number per plant. To calculate total seed weight (and number) per reproductive plant, we summed across known values for the primary ear and estimated values for the secondary ear. The latter assumed that the proportion of the primary ear's weight that was dedicated to seed was similar for the secondary ear. By summing weight or number of seeds across all ears on each plant, we estimated a total seed weight or total seed number per reproductive plant. In addition to total seed weight or total seed number per reproductive plant, we calculated the total seed weight or total seed number per emerged seedling. We did so by multiplying the proportion of plants that reproduced by the mean weight or number of seeds per reproductive plant.

\section{Data analysis}

All analyses were performed on plot means of fitness components and flowering traits using generalized linear mixed models (SAS, 9.4; Proc Glimmix) to discern any effects of environmental conditions (E: year and garden location) as well as of genetic factors (G: elevation, community, and population of maize origin) and $\mathrm{G} \times \mathrm{E}$ interactions. All models included year of experiment, garden location, elevation of maize origin, and their two- and three-way interactions as fixed factors; block within year and garden, community of maize origin within elevation, population of maize origin within community, and interactions between fixed and random factors were deemed random. Random factors were tested for whether their contribution to variation was significantly greater than zero using a $\mathrm{X}^{2}$ analysis comparing - $2 \log$ likelihood $(-2 L L)$ values between models with and without the factor of interest (using a covtest statement in Proc Glimmix). Least-squares means of fixed factors were used for presentation. Re-analyses of the full model separately for each elevation or each community resulted in a loss of power, so we increased our $P$ value cut-off for evaluation of effects of community and population simply to shed light on the likely sources from which significance in overall analyses had stemmed. We did not perform this reanalysis for ASI or fitness components since, except for in the case of weight per seed, they had not been significant for community in the full analysis. Finally, we calculated the Pearson correlation coefficients and their 95\% confidence intervals between total seed weight (or number) per reproductive plant and either flowering variables or weight per seed using data for each plant rather than plot means.

\section{Results}

Local adaptation of the landraces

We consistently found significant interactions among the fixed effects of year, garden location, and elevation of maize origin for fitness components (Table 1). The norms of reaction of landraces from the three elevational origins across the garden locations often differed in ways indicative of local adaptation. Total seed weight per reproductive plant and per emerged seedling both showed classic local adaptation patterns in 2011 with the local landrace doing best at each garden (Figs. 2C, 3A). In 2012, the lowland landraces did best in their local garden, and the other landraces trended to do best in their local garden (Figs. 2D, 3B); they were not significantly different from at least one other elevational type. Weight per seed indicated local adaptation, since the local landrace usually had the heaviest seed or matched the type that did (Fig. 2G, $\mathrm{H})$. Local adaptation was also visible in proportion of plants that never flowered and that only tasseled (Fig. 4A-D). In general, the local types maintained normal flowering better than non-local ones, though the highland landraces seemed to have a surprising propensity towards reduced flowering even under local conditions (especially Fig. 4C, D).

Not all fitness components pointed so clearly to local adaptation, however. Of particular note were survival to reproduction (Fig. 2A, B) and total seed number (rather than weight) per reproductive plant and per emerged seedling (Figs. 2E, 3C, D). For these fitness components, the highland landraces had little advantage in their local garden; the midland landraces had little advantage over the lowland landrace in the $1550 \mathrm{~m}$ garden, except for with survival in 2012; and the lowland landraces had great advantage in their local garden (Figs. 2A, B, E, F, 3C, D).

Flowering traits of landraces and their correlation with fitness components

For flowering time traits, we found interactions between year and garden, as well as between garden 


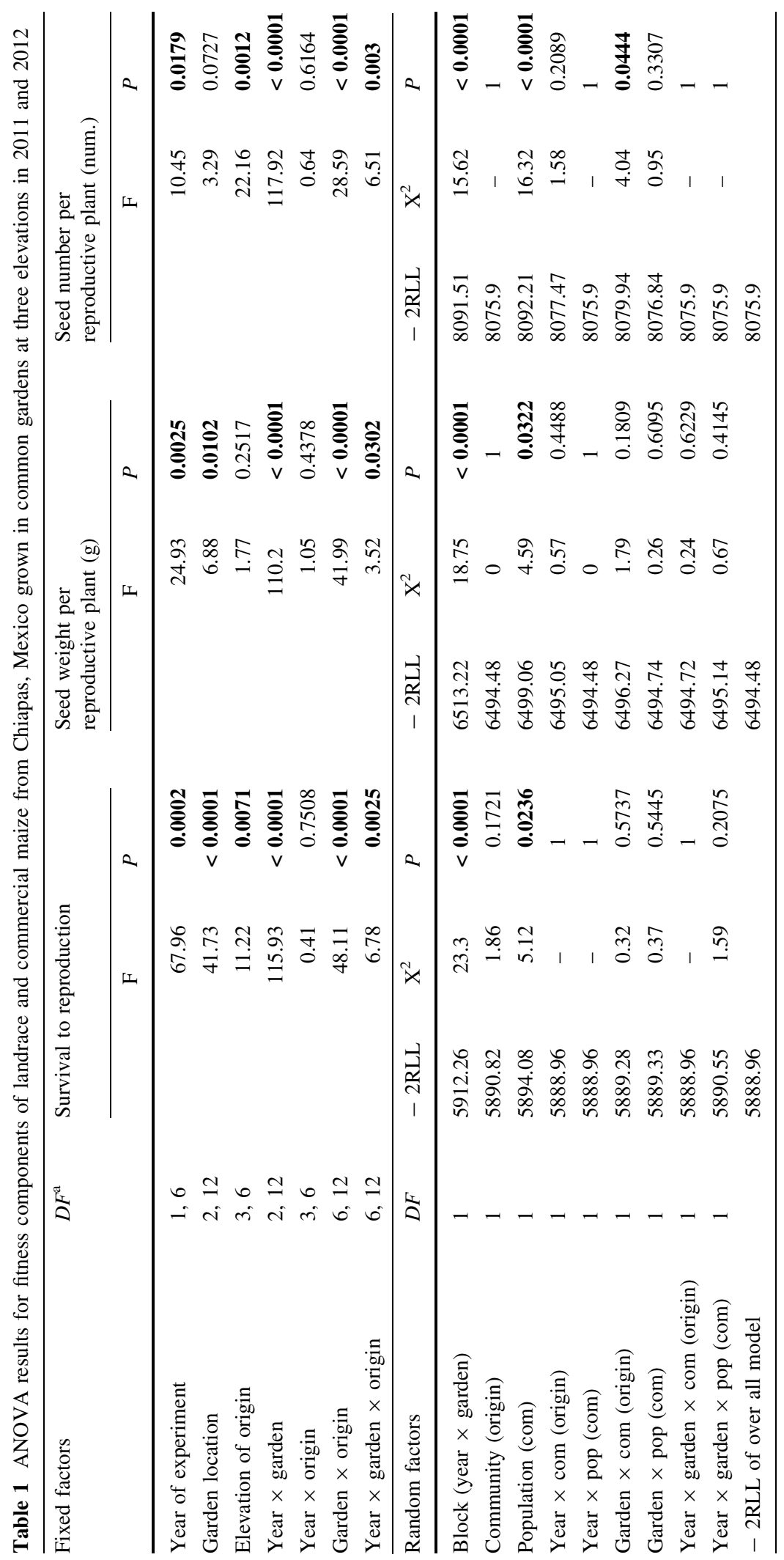




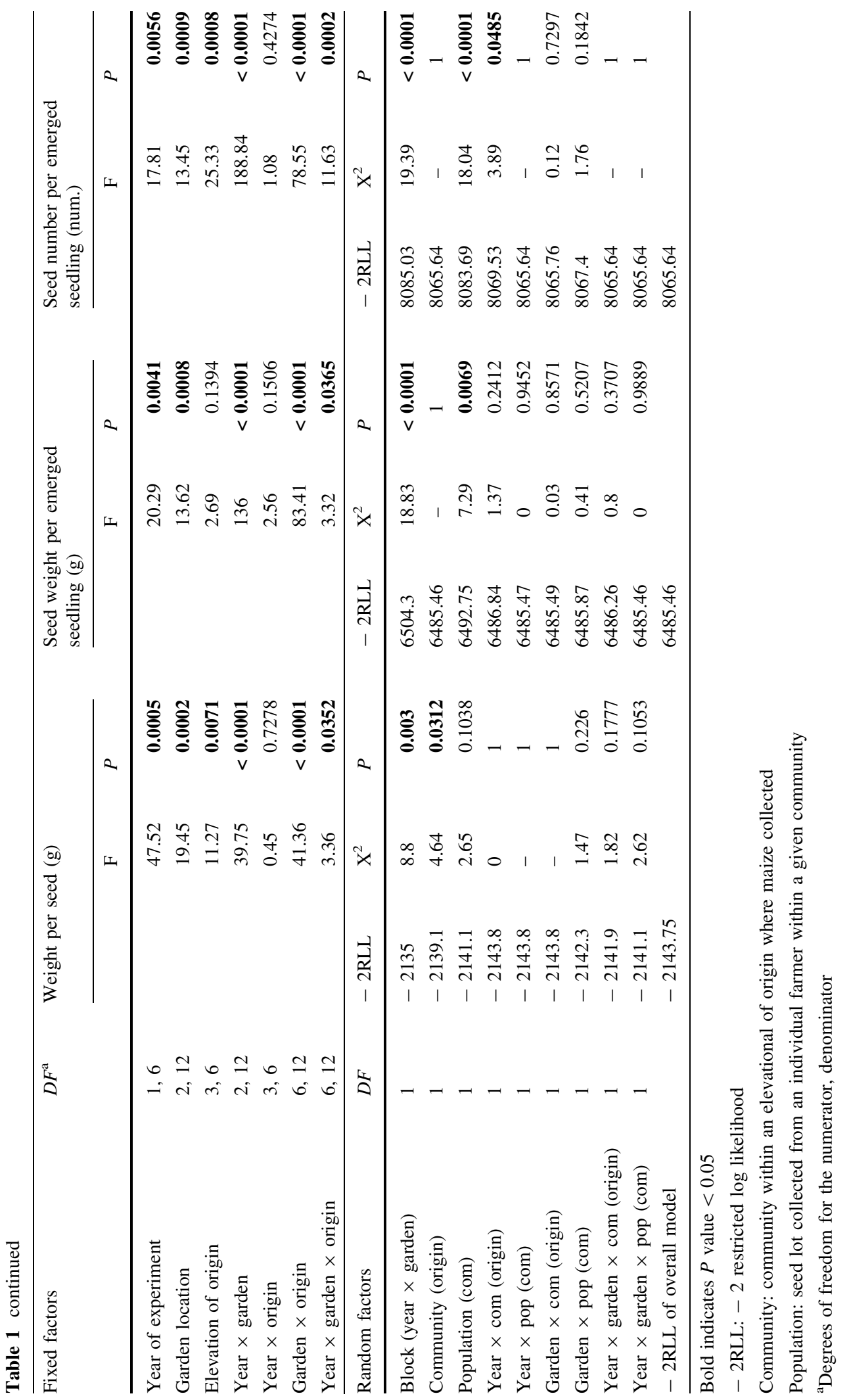


and elevation, affected their variation; however, the three-way interaction of these predictor variables did not (Table 2). While the interactions influencing ASI show that local types tend to have the shortest ASI (Fig. 4I, J), individual male and female flowering times were not consistently early or late for the local type (Fig. 4E-H). All flowering variables (tasseling time, silking time, and ASI) had negative correlations with total seed weight and total seed number per reproductive plant, though the strength and significance of the correlation varied by garden and maize origin (Fig. 5). Of note is that correlations tended to be most strongly negative in the $600 \mathrm{~m}$ garden as compared to the other gardens in 2011, although based on confidence intervals (data not show), only half of these trends were significant. This pattern did not repeat in 2012 (Fig. 5).

Correlations between individual seed weight and seed production

We saw strong positive correlations between weight per seed and total weight of seed per reproductive plant, with 21 of 24 correlations being significant (Supporting Information Table 3). By contrast, we calculated weaker and sometimes negative correlations between weight per seed and total number of seeds per reproductive plant, with only 11 of 24 correlations being significant (Supporting Information Table 3). Interestingly, when landraces were grown in their local garden, they did not have significant correlations between weight per seed and the total number of seeds per reproductive plant. Landraces brought to a higher elevation tended to have significant negative correlations between these two traits (Supporting Information Table 3).

\section{Relative performance of commercial varieties}

Commercial varieties tended to perform similarly to the lowland landraces in most total fitness measures, as well as in fitness components; however, they did significantly better than the lowland landraces in total number of seed per emerged seedling at the $600 \mathrm{~m}$ garden in 2011 (Fig. 3C). Further, they also outperformed the lowland landraces in the $2100 \mathrm{~m}$ garden in 2012 (Fig. 3D), thus being slightly better at producing many seed while out of place (at least under the excellent conditions at that garden in 2012). Flowering time variables showed few differences between landraces and commercial varieties, though the commercial varieties trended to having the shortest time to flower (Fig. 4E-H) and the shortest ASI (except in the highlands in 2011; Fig. 4I, J).

Structure of genetic variation among populations and communities

The effect of population of maize origin within community (averaged across all gardens and years) dominated the results of our random effects (Tables 1, 2). For all fitness components (except weight per seed) and for all three flowering traits, variation due to population within community was significantly different from zero. For tasseling and silking time and weight per seed, there was also significant variation due to community within elevation. For tasseling time, there was a significant interaction between garden elevation and population within community. Thus, we find apparently more variation among populations and communities for flowering traits than for fitness components. Yet, we also found that, while maize collected within elevations and communities can vary, their responses to variable environmental conditions (e.g., year and garden) remains similar.

To clarify how generalized these effects of community and population were, we reanalyzed the data by elevation and community, respectively. In a reanalysis of tasseling and silking time by elevation, we found variation among communities within an elevation for landraces from both the midland and highland elevations $(P<0.05$; Supporting Information Table 4). We found only one weak three-way interaction between year, garden, and community for midland landraces for silking time $(P<0.05$; Supporting Information Table 4). In a similar reanalysis by community this time (data not shown), only two of the communities where maize had been collected, as well as the improved varieties, had significant variation among populations for fitness components using a $P$ value of 0.15 . Five of the nine communities in which landraces were collected, as well as the commercial varieties, had differences among populations for tasseling and/or silking time; one community and the commercial varieties had populations that differed in ASI. Fitness components and flowering time variables were also affected by some two- and three-way 

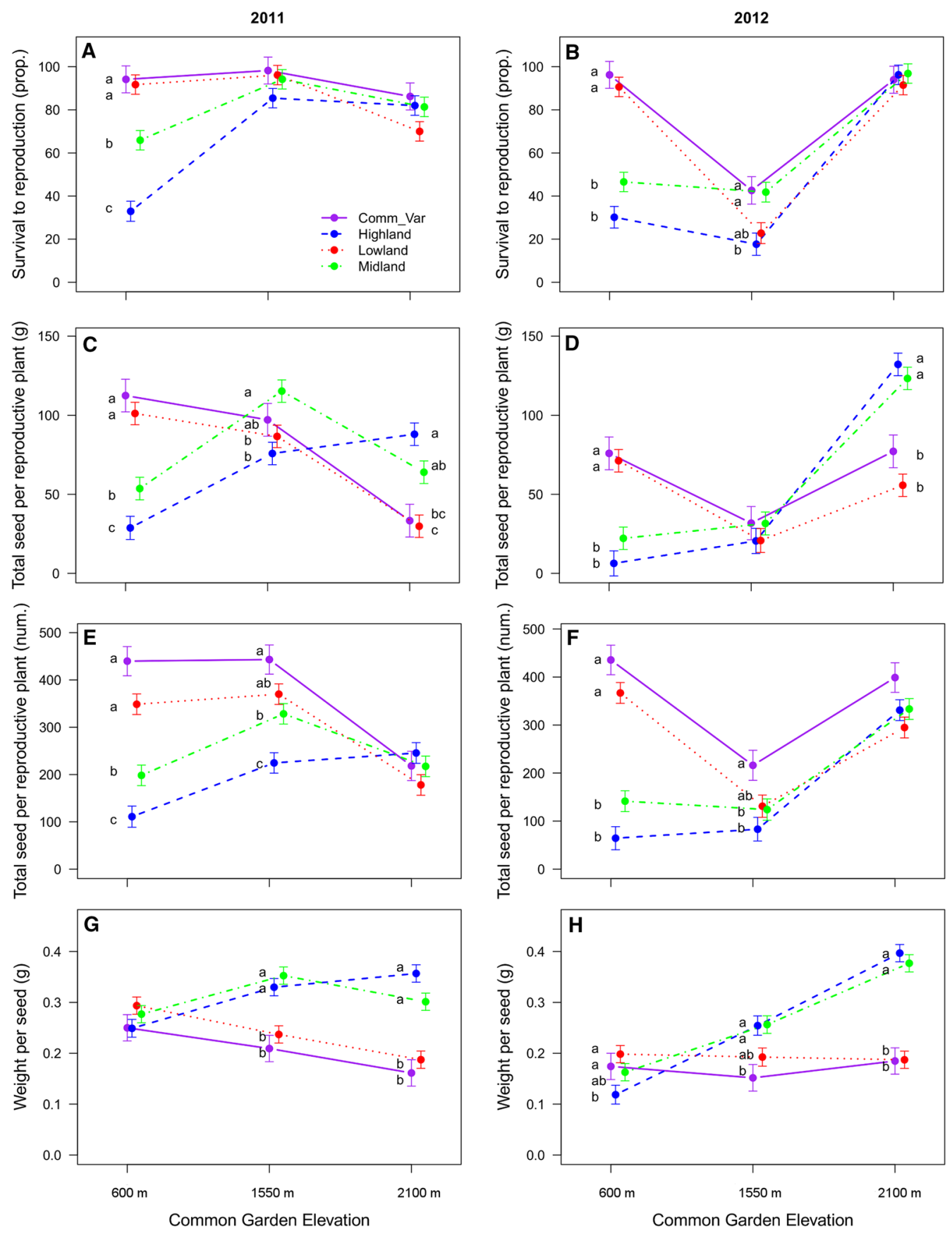

Fig. 2 Fitness components of landrace and commercial maize across common garden elevations in Chiapas, Mexico. Separate columns for 2011 (left) and 2012 (right) data for survival to reproduction, total seed per reproductive plant $(\mathrm{g})$, total seed per reproductive plant (num.), and weight per seed (g). Least squares means and SE bars. Maize type means within a garden

accompanied by different letters differ from one another using a Tukey-Kramer adjustment for multiple comparisons. Where no letters are present, there were no significant differences. Comm_var commercial varieties, highland highland landraces, midland midland landraces, lowland lowland landraces 
interactions between population, year, and garden, though they dispersed across traits and communities.

\section{Discussion}

This study has confirmed the local adaptation of landraces of maize to their altitudes of origin in Chiapas, Mexico. Though landraces have been understood to be locally adapted and their definition often includes adaptation (e.g., Zeven 1998), few studies have actually empirically tested the veracity of this evolutionary concept. Here we show that local adaptation can be identified in fitness components, although patterns can vary across years. Flowering time variables (especially ASI) that correlate with
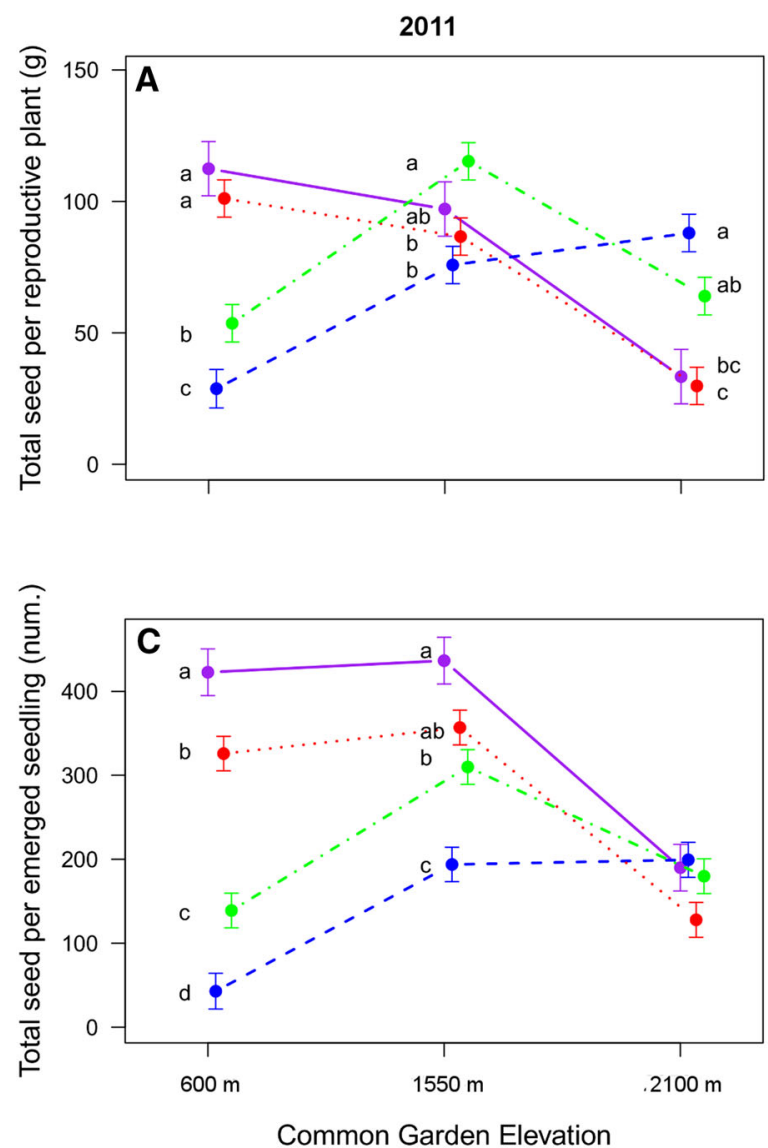

Fig. 3 Total fitness, a trait that combines the fitness components of survival and total seed variables for landrace and commercial maize across common garden elevations in Chiapas, Mexico. Separate columns for 2011 (left) and 2012 (right) data for total seed per emerged seedling ( $\mathrm{g}$ ) and total seed per emerged seedling (num.). Least squares means and SE bars. fitness components, may serve as indicators of adaptation or maladaptation as plants experience different environments. We also found that local landraces usually performed better than, or as well as, improved varieties available in the region reconfirming the confidence local farmers have in their saved seed. While there was some variation among maize collected from each elevation, the underlying patterns of local adaptation (e.g., their responses across environments) seem to be shared. Thus, we have improved our understanding of the form that local adaptation takes in this system, while also clarifying the degree to which quantitative genetic variation is found within elevations and communities (i.e., the structure of variation) in this center of crop diversity.
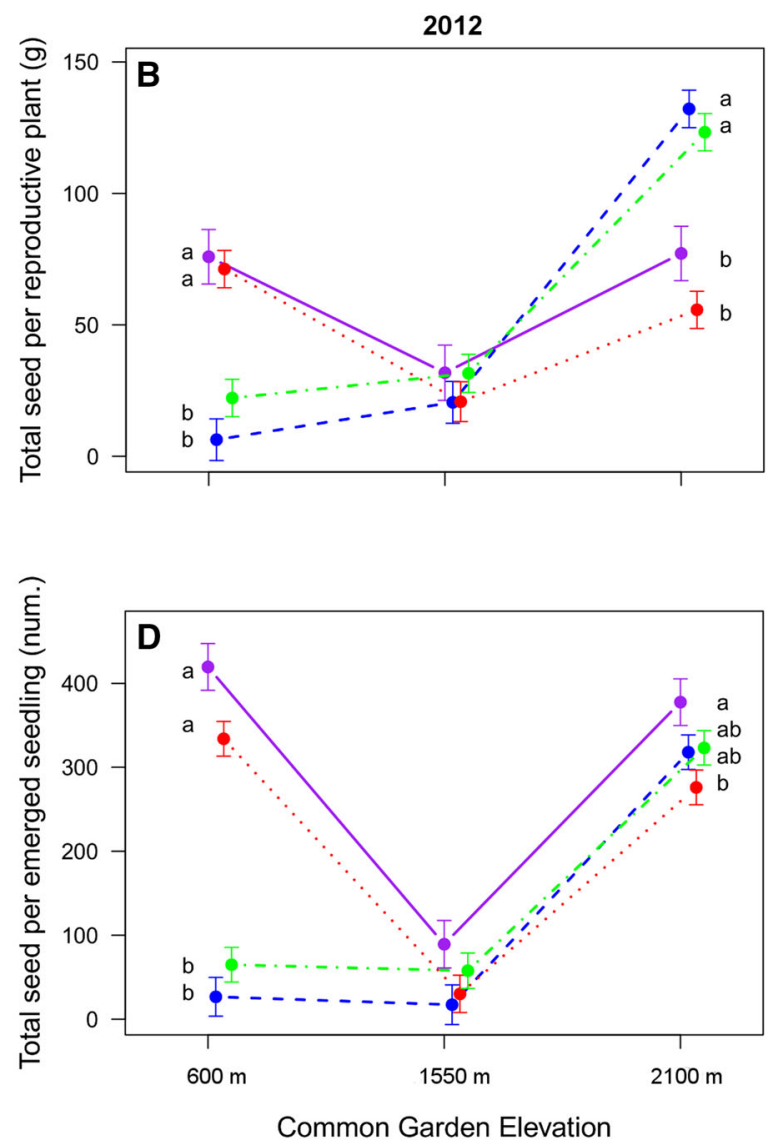

Maize type means within a garden accompanied by different letters differ from one another using a Tukey-Kramer adjustment for multiple comparisons. Where no letters are present, there were no significant differences among types. Comm_var commercial varieties, highland highland landraces, midland midland landraces, lowland lowland landraces 

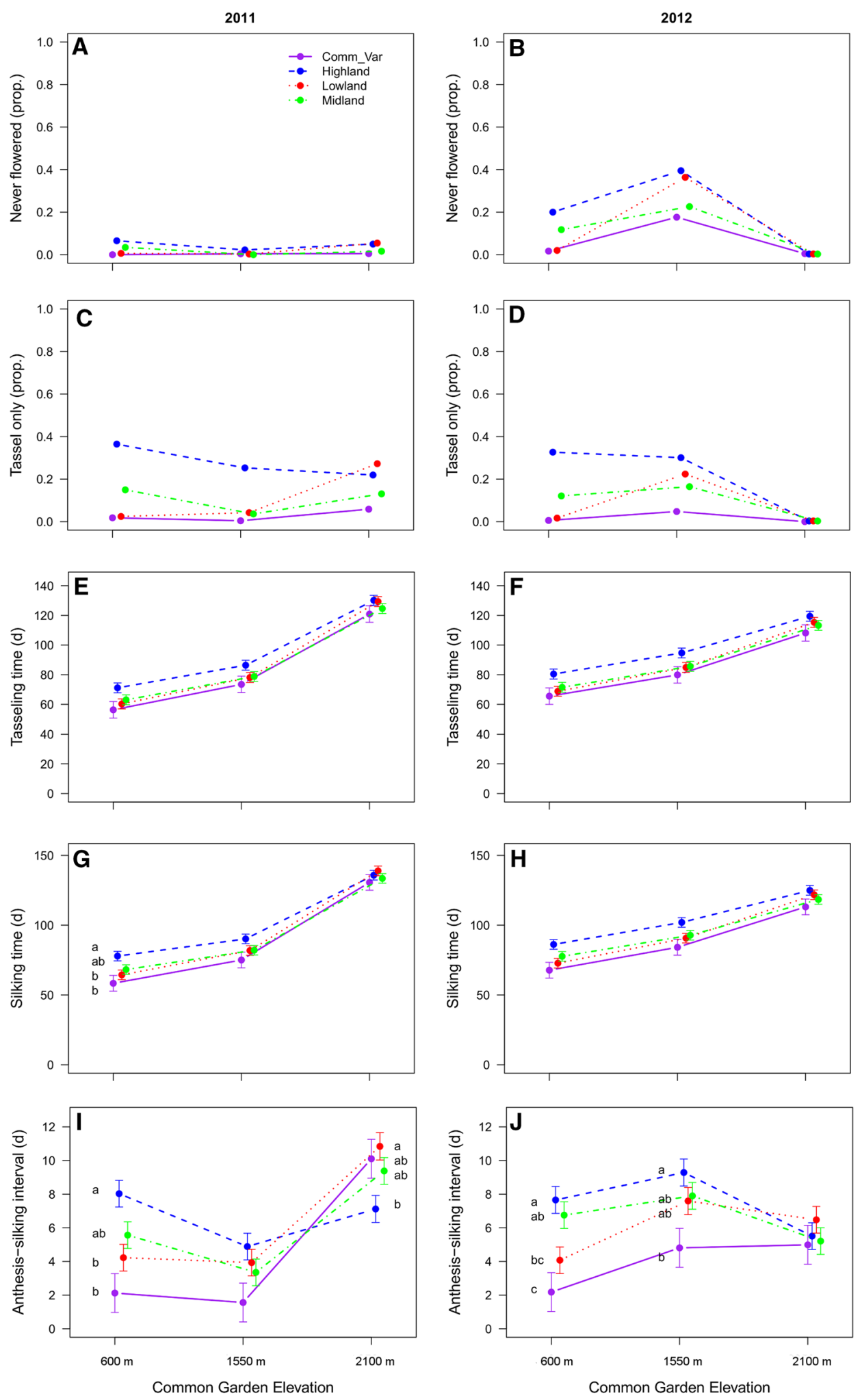
4Fig. 4 Flowering variables of landrace and commercial maize across common garden elevations in Chiapas, Mexico. Separate columns for 2011 (left) and 2012 (right) data for never flowered (prop.), tasseled only (prop.), tasseling time (d), silking time (d), and anthesis-silking interval (d). Data are presented as direct proportions (A-D) and least squares means (with SE bars) (EJ). Mean separation was not performed for A-D (see "Methods"). For $\mathbf{E}-\mathbf{J}$, maize type means within a garden accompanied by different letters differ from one another using a TukeyKramer adjustment for multiple comparisons. Where no letters are present, there were no significant differences. Comm_var commercial varieties, highland highland landraces, midland midland landraces, lowland lowland landraces

Indicators of local adaptation

We found stronger indications of local adaptation to elevation here than we have seen in past research. Previous experiments revealed asymmetrical local adaptation, with highland landraces having more trouble producing under midland conditions than was noted for midland and lowland landraces producing under highland conditions (Mercer et al. 2008). Our elucidation here of the year-to-year variation at each location indicates that yearly local conditions affect the patterns (and appearance) of local adaptation. Recent work in Oaxaca, Mexico did not identify local adaptation of maize landraces (Orozco-Ramírez et al. 2014), which may had been due to effects of elevation and ethnicity being inseparable and/or annual variation.

The ability to flower, a fitness component, indicated local adaptation. Thus, reduced flowering allowed us to view (mal)adaptation in our experiments. Plants that did not flower at all or only tasseled at a given location tended to be those not local to the place. These flowering limitations greatly influenced the number of plants that flowered normally (with both tassels and silks). As a result, we can see a maladaptation gradient from plants that did not flower at all to those that could only donate pollen to the next generation to those that could donate pollen and produce seed. This kind of clarity on how changes in the environment affect ability to flower (and thereby reproduce) may be important to understand other crop systems, as well.

Shorter ASI appears to be one candidate mechanism for local adaptation. ASI represents floral synchrony in maize (Campbell et al. 2013), improving pollination in this monoecious crop. ASI was shortest for the local landraces (when there were differences).
As we might have expected, we found that reduced synchrony (i.e., higher ASI) negatively correlated with greater reproduction, a correlation that appears to be stronger (or tighter) at lower elevations. Plant breeders have found that the correlations between ASI and yield strengthen when maize is faced with stress, so perhaps the shorter growing season in the lower elevations provided some form of stress (e.g., moisture stress; Bolanos and Edmeades 1996), thereby strengthening this relationship. Nevertheless, the droughty year in the midland garden did not stand out in this way. Interestingly, the highland landraces had surprisingly weak or absent correlations between ASI and reproduction when grown out of place in the lowlands and their ASI was nearly twice as long as that of the local type in that environment. Perhaps extreme maladaptation drove greater variation in ASI, but not in the uniformly low fitness components registered for highland landraces in the lowland garden, making the relationship weak or non-linear. The lower ASI of our commercial varieties (especially at lower elevation) indicate an effect of improvement on this trait; improvement of maize in the US has similarly reduced ASI values (Duvick 2005). In sum, ASI may be seen to be an indicator of adaptation (when low) or an indicator of stress (when high), but also a trait differentiated by breeding. Further study of how ASI may be differentially selected upon by environmental conditions is warranted.

Trade-offs influencing local adaptation

Fitness components and total fitness measures employing total seed weight (i.e., akin to per plant yield) clearly pointed to local adaptation, while those relying on seed number (i.e., Darwinian fitness) provided a less convincing case. Specifically, the lowland landraces (and related commercial varieties) suffered less when out of place when fitness measures incorporate number, not grams, of seeds per plant, which was untrue for highland landraces out of place. This appears to be due to the lighter, more copious seeds that lowland landraces produced and the fewer, heavier seeds that midland and highland landraces produced. This discrepancy in apparent local adaption depending on the measure of fitness begs the question of whether yield or Darwinian fitness is a better representation of fitness in crop systems. With maize, the phenotype of the ear mainly determines whether a 
Table 2 ANOVA results for flowering traits landrace and commercial maize from Chiapas, Mexico grown in common gardens at three elevations in 2011 and 2012

\begin{tabular}{|c|c|c|c|c|c|c|c|c|c|c|}
\hline \multirow[t]{2}{*}{ Fixed factors } & \multirow[t]{2}{*}{$D F^{\mathrm{a}}$} & \multicolumn{3}{|c|}{ Tasseling time } & \multicolumn{3}{|c|}{ Silking time } & \multicolumn{3}{|c|}{ Anthesis-silking interval } \\
\hline & & & $\mathrm{F}$ & $P$ & & $\mathrm{~F}$ & $P$ & & $\mathrm{~F}$ & $P$ \\
\hline Year of experiment & 1,6 & & 3.59 & 0.1071 & & 2.07 & 0.2002 & & 0.09 & 0.7789 \\
\hline Garden location & 2,12 & & 2025.1 & $<0.0001$ & & 1856.73 & $<0.0001$ & & 11.81 & 0.0015 \\
\hline Elevation of origin & 3,6 & & 1.9 & 0.2309 & & 2.16 & 0.1944 & & 4.34 & 0.0601 \\
\hline Year $\times$ garden & 2,12 & & 126.15 & $<0.0001$ & & 115.34 & $<0.0001$ & & 40.54 & $<0.0001$ \\
\hline Year $\times$ origin & 3,6 & & 1.53 & 0.2996 & & 1.76 & 0.2543 & & 1.3 & 0.3578 \\
\hline Garden $\times$ origin & 6,12 & & 9.16 & 0.0007 & & 27.57 & $<0.0001$ & & 7.43 & 0.0017 \\
\hline Year $\times$ garden $\times$ origin & 6,12 & & 1.07 & 0.4311 & & 1.87 & 0.1671 & & 1.36 & 0.3059 \\
\hline Random factors & $D F$ & $-2 \mathrm{RLL}$ & $X^{2}$ & $P$ & -2 RLL & $X^{2}$ & $P$ & $-2 R L L$ & $X^{2}$ & $P$ \\
\hline Block (year $\times$ garden $)$ & 1 & 4182.49 & 78.52 & $<0.0001$ & 4430.98 & 69.45 & $<0.0001$ & 3637.84 & 13.95 & 0.0002 \\
\hline Community (origin) & 1 & 4120.72 & 16.75 & $<0.0001$ & 4374.2 & 12.68 & 0.0004 & 3623.89 & 0 & 1 \\
\hline Population (com) & 1 & 4140.82 & 36.84 & $<0.0001$ & 4391.25 & 29.72 & $<0.0001$ & 3631.42 & 7.53 & 0.0061 \\
\hline Year $\times$ com $($ origin $)$ & 1 & 4104.64 & 0.67 & 0.4128 & 4362.51 & 0.99 & 0.32 & 3623.97 & 0.08 & 0.7829 \\
\hline Year $\times$ pop $(\mathrm{com})$ & 1 & 4104.72 & 0.74 & 0.3887 & 4362 & 0.47 & 0.4928 & 3623.89 & 0 & 1 \\
\hline Garden $\times$ com (origin) & 1 & 4105.67 & 1.7 & 0.1923 & 4361.53 & - & 1 & 3624.86 & 0.97 & 0.3258 \\
\hline Garden $\times$ pop $(\mathrm{com})$ & 1 & 4108.26 & 4.29 & 0.0384 & 4361.53 & - & 1 & 3623.98 & 0.08 & 0.7717 \\
\hline $\begin{array}{l}\text { Year } \times \text { garden } \times \\
\text { com }(\text { origin })\end{array}$ & 1 & 4103.97 & 0 & 1 & 4362.02 & 0.49 & 0.4823 & 3625.18 & 1.29 & 0.2556 \\
\hline $\begin{array}{l}\text { Year } \times \text { garden } \times \text { pop } \\
(\text { com })\end{array}$ & 1 & 4104 & 0.03 & 0.8699 & 4363.49 & 1.97 & 0.1606 & 3624.77 & 0.88 & 0.3474 \\
\hline-2 RLL of overall model & & 4103.97 & & & 4361.53 & & & 3623.89 & & \\
\hline
\end{tabular}

Bold indicates $P$ value $<0.05$

-2 RLL: -2 restricted $\log$ likelihood

Community: community within an elevational of origin where maize collected

Population: seed lot collected from an individual farmer within a given community

${ }^{\mathrm{a}}$ Degrees of freedom for the numerator, denominator

farm family eats or saves it for next year's seed (Louette and Smale 2000). High seed number per ear might be considered during farmer selection, but ear weight is likely to be of greatest interest. Ears with greater numbers of seeds will contribute more seed to the subsequent generation. Nevertheless, plants coming from larger seeds produced on ears with fewer seeds may be afforded early season advantages or augmented yield due to their early size (Gambín and Borrás 2010). Clearly there are trade-offs between interpretation of adaptation using different measures of fitness; thus, we present both. Somewhat similar diversity at work in other types of crops, such as chile pepper, may mean that larger fruits selected by farmers may have unknown implications for the number or size of propagules inside.
The trade-off between the size or quality of seeds (here represented by weight per seed) and the number of seeds a plant produces has been well-studied in natural systems and crops (e.g., Sadras 2007). However, how this relationship shifts across genetic materials within a crop and across environmental conditions is still not well understood. Here the change in correlations between seed size and numbers of seeds with displacement to higher or lower elevations may indicate important variation in how different maize types respond to stress and in strategies for achieving high fitness. In fact, since seed weight per emerged or reproductive plant (yield) was similar at all gardens for the local landraces in their best years, different ways of achieving high fitness may be equally successful under beneficial local conditions. 

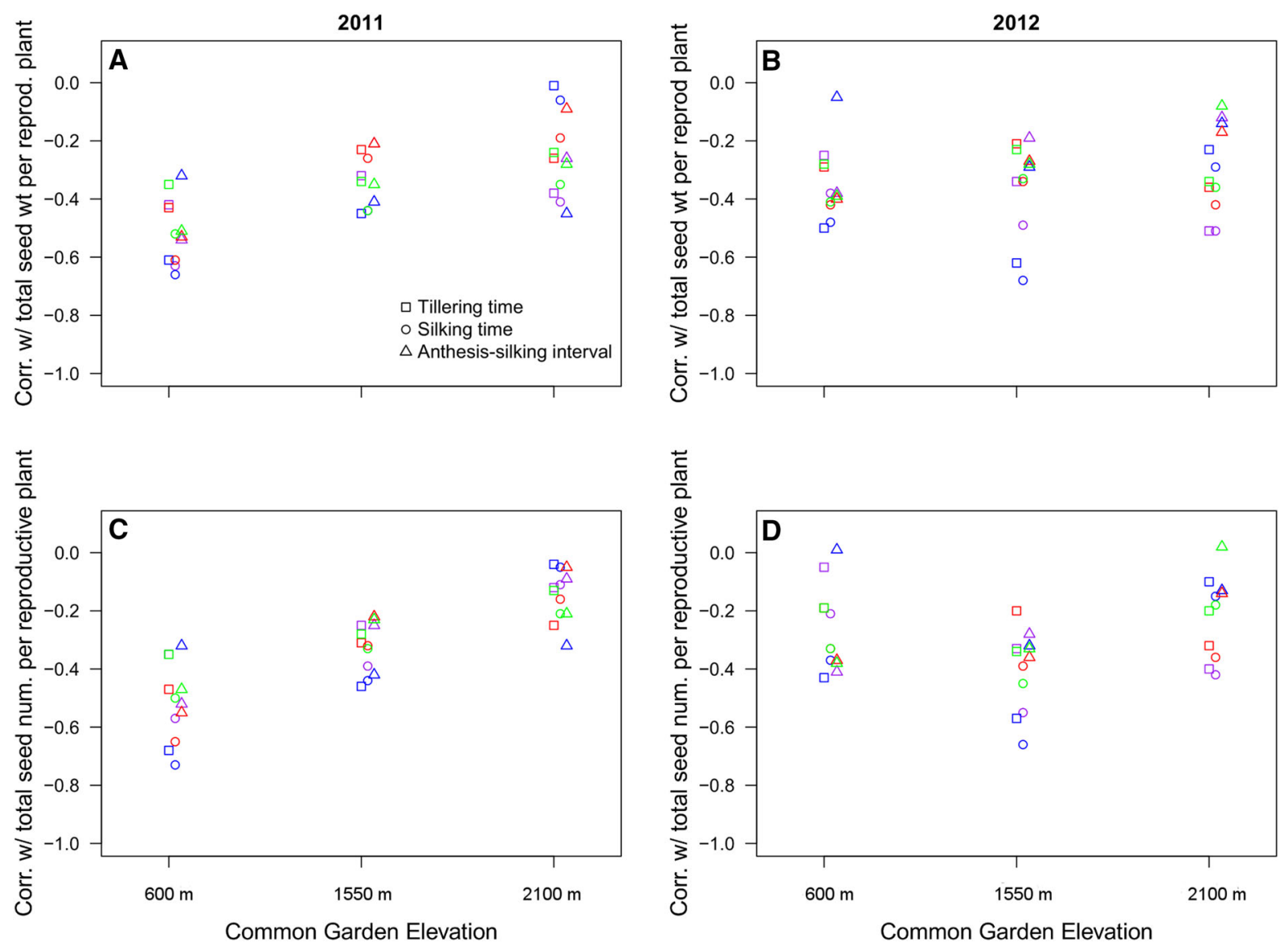

Fig. 5 Correlations between total seed per reproductive plant (as weight in $\mathbf{A}$ and $\mathbf{B}$ and as number in $\mathbf{C}$ and $\mathbf{D}$ ) and flowering time variables in landrace and commercial maize across common garden elevations. Symbols indicate correlations of

By contrast, under the most dire conditions (the 2012 midland garden), weight per seed was not as dramatically affected as whole plant fitness. Thus, survival to reproduction and the number of seeds produced per reproductive plant, but not the weight per seed, were important causes for the fitness declines in that garden in 2012.

Commercial varieties not distinguished from landraces

The commercial varieties studied here are available to farmers in Chiapas, though highland farmers rarely use them and they are not sold there. Since use of commercial varieties and farmer-management of advanced generations derived from commercial varieties can reduce crop diversity (van Heerwaarden et al.

total seed with: square $=$ tillering time; circle $=$ silking time; triangle $=$ anthesis-silking interval. purple $=$ commercial variety; red = lowland landraces; green = midland landraces; blue $=$ highland landraces. $($ Color figure online $)$

2009), their incorporation in centers of crop diversity can be problematic. Nevertheless, government programs in Mexico have encouraged farmers to switch from their landraces to commercial varieties. Here we find that current commercial varieties have lower yield than highland landraces under highland conditions and thus care should be taken in promoting them to highland farmers. Still, we can see that commercial varieties do have virtues: they flower readily at all locations and have a relatively low ASI; they have consistently high survival to reproduction and they produce a large number of seeds per plant, especially under lowland conditions. Yet, despite past breeding, commercial varieties were rarely differentiated from the lowland landraces with whom they share the same genetic background (i.e., lowland Tuxpeño race), though they often trended towards having higher 
values for fitness components and total fitness. Thus, while commercial varieties available to farmers did seem to have value, they did not yield more than landraces and did not tolerate high elevation. In sum, by replanting seeds from their local landraces, farmers maintain their yields.

Others making comparisons between landraces and commercial varieties have often found landraces do well under highland conditions and in marginal environments, in particular when the comparison is made against collections of landraces instead of only one sample (Muñoz 2005; Perales 2016). More recent Mexican programs, such as PROMAC (Maize Landraces Program of the Mexican Government), have begun to encourage farmers to grow their own landraces rather than rely on commercial varieties. While these programs often originate from interest in conservation of genetic diversity and preservation of cultural heritage, our data show that they also have an agronomic basis, especially at higher elevations. Further exploration of the benefits of landraces are warranted in other crop centers of diversity.

Few differences among maize from different communities and more among populations

The random factors of community and population in our statistical model described the origin of the maize landraces and allowed us to better understand the structure of adaptive variation within a landscape of maize. We found significant variation within elevations of origin for flowering time variables (but not ASI or fitness components). Thus, flowering time variables may better distinguish communities within an elevation and populations within a community than do fitness components or ASI. Others have found variation for flowering time among maize populations collected between 1310 and $1830 \mathrm{~m}$ in Oaxaca, Mexico (Pressoir and Berthaud 2004b) and at lower elevations ( $~ 600 \mathrm{~m}$ ) in Chiapas, Mexico (van Heerwaarden et al. 2009). However, unlike in our study, Pressoir and Berthaud (2004b) found fitness components (i.e., ear, kernel, and cob traits) to be more differentiated within and among communities than flowering time traits by comparing $\mathrm{Q}_{\mathrm{ST}}$ values (i.e., genetic differentiation of quantitative traits). Here, maize from lowland communities appeared to have the most uniform flowering time, perhaps due to longer distance seed exchange (Bellon et al. 2011) or more intense selection on reduced flowering times in keeping with their shorter growing seasons. Given this possibility and the apparent correlations between flowering time variables and fitness components, we plan to expand this line of inquiry to formal selection analyses (Lande and Arnold 1983; Etterson 2004) on these traits.

Flowering time variation is interesting from a gene flow perspective. Farmers may intentionally maintain differences in flowering time to minimize gene flow (Bellon and Brush 1994; Louette et al. 1997), but other sources of variation can also affect gene flow and thus genetic differentiation (quantitative or molecular). $\mathrm{F}_{\mathrm{ST}}$ values (i.e., a measure of molecular genetic differentiation) among maize from different villages or among populations within a village (Pressoir and Berthaud 2004a; Perales et al. 2005) tend to be low. This may indicate high homogenization (due to seed sharing and pollen flow), though isolation by distance may be present at larger scales $(>50 \mathrm{~km})$ (Vigouroux et al. 2008; but see Van Etten et al. 2008). Social factors, such as ethnolinguistic diversity, have been shown to play a role in differentiating populations possibly due to reduced seed exchange (Perales et al. 2005; OrozcoRamírez et al. 2016). However, we should recall that the structures of quantitative and molecular genetic variation rarely correlate (McKay and Latta 2002). Thus, we do see cases where variation in phenotypic traits (both flowering and fitness components) occurs despite high gene flow, reducing pollen-mediated gene flow within some elevations and some communities. Some variation in phenotype may be due to past exchange of unusual seed, thereby increasing random variation within communities.

Implications for climate change

The landraces of many agricultural crops will be under stress to adapt to climate change. Many have proposed possible paths to maintain landrace productivity in the face of changing conditions, including the following: in situ plastic responses and adaptive evolution of the landraces; introduction of appropriate landraces to areas with predicted climates that resemble the conditions under which they previously evolved; selection by farmers and/or by researchers for traits beneficial under the new conditions, including through participatory or evolutionary breeding strategies; and other complementary adaptation capacities strategies 
(Ceccarelli et al. 2010; Mercer and Perales 2010; Bellon et al. 2011; Hellin et al. 2014; Ceccarelli et al. 2010; Mercer et al. 2018).

Experimenting with growing maize at lower (i.e., warmer) elevations than those to which it is accustomed can produce plastic responses that may possibly mimic climate change responses. Here, all fitness component values were reduced when midland and highland landraces were exposed to lower elevations where temperatures are warmer. Flowering timing grew shorter for all landraces at lower garden elevations indicating a hastening of development (as expected from Parmesan and Yohe 2003 and others) with increased temperature, while ASI generally increased. Thus, we cannot assume that plastic responses will maintain current productivity of maize landraces with global warming.

Yet, gradual climate change may require less extreme plastic responses than needed here to maintain productivity in maize landraces since landraces may also adapt to climatic change naturally or be selected by farmers to maintain productivity over time (Mercer and Perales 2010), as was seen in pearl millet (Vigouroux et al. 2011). Such adaptation may be fueled by adaptive alleles provided by gene flow from other populations (i.e., seed exchange and hybridization) (Bellon et al. 2011) or through more concerted breeding efforts (Hellin et al. 2014).

Nevertheless, the declines in productivity we observed might certainly have implications for subsistence farmers in the region whose diets depend on maize. Our results are in line with global modeling of corn production with climate change, which indicates that production can be estimated to decline by $7.4 \%$ for Mexico by 2055 from its modeled 1990 baseline; yet this represents a $44.4 \%$ decline from actual yields reported in 2000 (Jones and Thornton 2003), so yearly variation is important to consider. In general, local yield declines in the tropics should be greater than in temperate areas (World Bank 2012; IPCC 2014). Given our results, we might expect relative similarity in how genetic materials from a given community respond to environmental change since we saw few elevation- or community-specific $\mathrm{G} \times \mathrm{E}$ interactions; however, extreme years indicate that under some conditions, none of the diversity we assayed did well (for example, the midland garden in 2012). To counter these declines, it will be crucial to maintain and enhance the adaptive plastic and evolutionary (gene flow and selection) capacity of these systems. The system's ability to reshuffle genes to best address environmental change may dwarf our own. Nevertheless, these data also indicate the need to identify geographical areas where locally adapted landrace crop production may suffer most with climate change, spurring investigations into the possibility for biological adaptation, breeding, and adaptation of cultural practices to avert loss of livelihoods and genetic diversity.

Acknowledgements The authors would like to thank Á. Martínez, F. Pérez, B. Pace, M. Kost, and A. Weiss for work in the field and B. Pace, V. Bernau, and members of FLORUM at UBC (especially A. Angert) for helpful comments on previous drafts of the manuscript. We thank the National Geographic Society (Committee for Research and Exploration Grant No. 9178-12) for partially funding this research. Salaries and research support were also provided by State and Federal funds appropriated to the Ohio Agricultural Research and Development Center, Ohio State University: Grant No. 2011-083 and manuscript no. HCS17-07.

\section{Compliance with ethical standards}

Conflict of interest The authors declare that they have no conflict of interest.

Data availability The datasets generated during and/or analyzed during the current study are available from the authors upon request.

Open Access This article is distributed under the terms of the Creative Commons Attribution 4.0 International License (http:// creativecommons.org/licenses/by/4.0/), which permits unrestricted use, distribution, and reproduction in any medium, provided you give appropriate credit to the original author(s) and the source, provide a link to the Creative Commons license, and indicate if changes were made.

\section{References}

Aguilar-Rangel MR, Montes RAC, González-Segovia E, RossIbarra J, Simpson JK, Sawers RJ (2017) Allele specific expression analysis identifies regulatory variation associated with stress-related genes in the Mexican highland maize landrace Palomero Toluqueño. PeerJ 5:e3737

Anderson E, Cutler HC (1942) Races of Zea mays: I. Their recognition and classification. Ann Mo Bot Gard 29:69-88

Angert AL, Schemske DW (2005) The evolution of species' distributions: reciprocal transplants across the elevation ranges of Mimulus cardinalis and M. lewisii. Evolution 59:1671-1684

Aquino P, Carrión F, Calvo R, Flores D (2001) Selected maize statistics. In: Pingali PL (ed) CIMMYT 1999-2000 world 
maize facts and trends: meeting world maize needs: technological opportunities and priorities for the public sector. CIMMYT, Mexico, pp 45-57

Bellon MR, Brush SB (1994) Keepers of maize in Mexico. Econ Bot 48:196-209

Bellon MR, Risopoulos J (2001) Small-scale farmers expand the benefits of improved maize germplasm: a case study from Chiapas, Mexico. World Dev 29:799-811

Bellon MR, Hodson D, Hellin J (2011) Assessing the vulnerability of traditional maize seed systems in Mexico to climate change. Proc Natl Acad Sci 108(33):13432-13437

Bellon MR, Mastretta-Yanes A, Ponce-Mendoza A, OrtizSantamaría D, Oliveros-Galindo O, Perales H, Acevedo F, Sarukhán J (2018) Evolutionary and food supply implications of ongoing maize domestication by Mexican campesinos. Proc R Soc B 285:20181049

Bolanos J, Edmeades GO (1996) The importance of the anthesis-silking interval in breeding for drought tolerance in tropical maize. Field Crop Res 48:65-80

Bragg JG, Supple M, Andrew RL, Borevitz JO (2015) Genomic variation across landscapes: insights and applications. New Phytol 207:953-967

Brush SB, Perales HR (2007) A maize landscape: ethnicity and agro-biodiversity in Chiapas Mexico. Agr Ecosyst Environ 121:211-221

Campbell LG, Luo J, Mercer KL (2013) Effect of water availability and genetic diversity on flowering phenology, synchrony and reproductive investment in summer squash. J Agric Sci 151:775-786

Ceccarelli S, Grando S, Maatougui M, Michael M, Slash M, Haghparast R, Rahmanian M, Taheri A, Al-Yassin A, Benbelkacem A, Labdi M (2010) Plant breeding and climate changes. J Agric Sci 148:627-637

Clausen J, Keck DD, Hiesey WM (1941) Regional differentiation in plant species. Am Nat 75:231-250

Ducrocq S, Madhur D, Veyrieras J-B, Camus-Kulandaivelu L, Kloiber-Maitz M, Presterl T, Ouzunova M, Manicacci D, Charcosset A (2008) Key impact of Vgt1 on flowering time adaptation in maize: evidence from association mapping and ecogeographical information. Genetics 178:2433-2437

Duvick DN (2005) The contribution of breeding to yield advances in maize (Zea mays L.). Adv Agron 86:83-145

Eagles HA, Lothrop JE (1994) Highland maize from central Mexico-its origin, characteristics, and use in breeding programs. Crop Sci 34:11-19

Etterson JR (2004) Evolutionary potential of Chamaecrista fasciculata in relation to climate change. 1. Clinal patterns of selection along an environmental gradient in the Great Plains. Evolution 58:1446-1458

Franks SJ, Sims S, Weis AE (2007) Rapid evolution of flowering time by an annual plant in response to climate fluctuation. Proc Natl Acad Sci 104:1278-1282

Gambín BL, Borrás L (2010) Resource distribution and the trade-off between seed number and seed weight: a comparison across crop species. Ann Appl Biol 156:91-102

Hadado TT, Rau D, Bitocchi E, Papa R (2010) Adaptation and diversity along an altitudinal gradient in Ethiopian barley (Hordeum vulgare L.) landraces revealed by molecular analysis. BMC Plant Biol 10:121
Hellin J, Bellon MR, Hearne SJ (2014) Maize landraces and adaptation to climate change in Mexico. J Crop Improv 28:484-501

IPCC (2014) Climate change 2014: synthesis report. In: Pachauri RK, Meyers LA (eds) Contribution of working Groups I, II, and III to the fifth assessment report of the intergovernmental panel on climate change. IPCC, Geneva

Jones PG, Thornton PK (2003) The potential impacts of climate change on maize production in Africa and Latin America in 2055. Glob Environ Change 13:51-59

Kawecki TJ, Ebert D (2004) Conceptual issues in local adaptation. Ecol Lett 7:1225-1241

Kost MA, Perales HR, Wijeratne S, Wijeratne AJ, Stockinger E, Mercer KL (2017) Differentiated transcriptional signatures in the maize landraces of Chiapas, Mexico. BMC Genom 18:707

Lande R, Arnold SJ (1983) The measurement of selection on correlated characters. Evolution 37:1210-1226

Lasky JR, Upadhyaya HD, Ramu P, Deshpande S, Hash CT, Bonnette J, Juenger TE, Hyma K, Acharya C, Mitchell SE, Buckler ES (2015) Genome-environment associations in sorghum landraces predict adaptive traits. Sci Adv 1:e1400218

Leimu R, Fischer M (2008) A meta-analysis of local adaptation in plants. PLoS ONE 3:e4010

Lenormand $\mathrm{T}$ (2002) Gene flow and the limits to natural selection. Trends Ecol Evol 17:4

Louette D, Smale M (2000) Farmers' seed selection practices and traditional maize varieties in Cuzalapa, Mexico. Euphytica 113:25-41

Louette D, Charrier A, Berthaud J (1997) In situ conservation of maize in Mexico: genetic diversity and maize seed management in a traditional community. Econ Bot 51:20-38

Luna MBM, Hinojosa RMA, Ayala GOJ, Castillo GF, Mejía CA (2012) Perspectives of the maize seed industry development in Mexico. Rev Fitotec Mex 35:1-7

Matsuoka Y, Vigouroux Y, Goodman MM, Sanchez GJ, Buckler E (2002) A single domestication for maize shown by multilocus microsatellite genotyping. Proc Natl Acad Sci 99:6080-6084

McKay JK, Latta RG (2002) Adaptive population divergence: markers, QTL and traits. Trends Ecol Evol 17:285-291

Mercer KL, Perales HR (2010) Evolutionary response of landraces to climate change in centers of crop diversity. Evol Appl 3:480-493

Mercer K, Matínez-Vásquez A, Perales HR (2008) Asymmetrical local adaptation of maize landraces along an altitudinal gradient. Evol Appl 1:489-500

Mercer KL, Vigouroux Y, Castañeda-Álvarez NP, de Haan S, Hijmans RJ, Leclerc C, McKey D, and Vanek S (2018) Crop evolutionary agroecology: genetic and functional dimensions of agrobiodiversity and associated knowledge. In: Zimmerer KS, de Haan S (eds) Agrobiodiversity: integrating knowledge for a sustainable future. Strüngmann forum reports, vol 24. MIT Press, Cambridge, MA (in press)

Muñoz A (2005) Centli-Maiz. Colegio de Postgraduados, Montecillo

Orozco-Ramírez Q, Brush SB, Grote MN, Perales H (2014) A minor role for environmental adaptation in local-scale 
maize landrace distribution: results from a common garden experiment in Oaxaca, Mexico. Econ Bot 68:383-396

Orozco-Ramírez Q, Ross-Ibarra J, Santacruz-Varela A, Brush S (2016) Maize diversity associated with social origin and environmental variation in Southern Mexico. Heredity 116:477-484

Parmesan C, Yohe G (2003) A globally coherent fingerprint of climate change impacts across natural systems. Nature 421:37-42

Perales H (2016) Landrace conservation of maize in Mexico: an evolutionary breeding interpretation. In: Maxted N, Ehsan Dullo M, Ford-Lloyd BV (eds) Enhancing crop genepool use: capturing wild relative and landrace diversity for crop improvement. CAB International, Wallingford, pp 271-281

Perales H, Golicher D (2014) Mapping the diversity of maize races in Mexico. PLoS ONE 9:e114657

Perales HR, Benz BF, Brush SB (2005) Maize diversity and ethnolinguistic diversity in Chiapas, Mexico. Proc Natl Acad Sci 102:949-954

Pressoir G, Berthaud J (2004a) Patterns of population structure in maize landraces from the Central Valleys of Oaxaca in Mexico. Heredity 92:88-94

Pressoir G, Berthaud J (2004b) Population structure and strong divergent selection shape phenotypic diversification in maize landraces. Heredity 92:95-101

Pyhajarvi T, Hufford MB, Mezmouk S, Ross-Ibarra J (2013) Complex patterns of local adaptation in teosinte. Genome Biol Evol 5:1594-1609

Sadras VO (2007) Evolutionary aspects of the trade-off between seed size and number in crops. Field Crop Res 100:125-138

Samberg LH, Fishman L, Allendorf FW (2013) Population genetic structure in a social landscape: barley in a traditional Ethiopian agricultural system. Evol Appl 6:1133-1145

Sanchez JJ, Goodman MM (1992) Relationships among the Mexican races of maize. Econ Bot 46:72-85

Sanchez JJ, Goodman MM, Stuber CW (2000) Isozymatic and morphological diversity in the races of maize of Mexico. Econ Bot 54:43-59

Sánchez JJ, Goodman MM, Rawlings JO (1993) Appropriate characters for racial classification in maize. Econ Bot 47:44-59

Schmidt A, Eitzinger A, Sonder K, Sain G, Rizo L, Rodriguez B, Hellin J, Fisher M, Läderach P, Vicente FS (2012) Tortillas on the roaster: Central America's maize-bean systems and the changing climate. Catholic Relief Services, International Center for Tropical Agriculture (CIAT), International Center for Maize and Wheat Breeding (CIMMYT)

Shaw RG, Etterson JR (2012) Rapid climate change and the rate of adaptation: insight from experimental quantitative genetics. New Phytol 195:752-765

Takuno S, Ralph P, Swarts K, Elshire RJ, Glaubitz JC, Buckler ES, Hufford MB, Ross-Ibarra J (2015) Independent molecular basis of convergent highland adaptation in maize. Genetics 200:1297-1312

Tiffin P, Ross-Ibarra J (2014) Advances and limits of using population genetics to understand local adaptation. Trends Ecol Evol 29:673-680

Tiranti B, Negri V (2007) Selective microenvironmental effects play a role in shaping genetic diversity and structure in a Phaseolus vulgaris L. landraces: implications for on-farm conservation. Mol Ecol 16:4942-4955

Valenzuela E, Cavazos T (2017) Datos climáticos del CLICOM del SMN a través de su plataforma web del CICESE. http:// clicom-mex.cicese.mx. Accessed 15 Nov 2007

Van Etten J, Fuentes López MR, Molina Monterroso LG, Ponciano Samayoa KM (2008) Genetic diversity of maize (Zea mays L. ssp. mays) in communities of the western highlands of Guatemala: geographical patterns and processes. Genet Resour Crop Evol 55:303-317

Van Heerwaarden J, Hellin J, Visser RF, van Eeuwijk FA (2009) Estimating maize genetic erosion in modernized smallholder agriculture. Theor Appl Genet 119:875-888

Vigouroux Y, Glaubitz JC, Matsuoka Y, Goodman MM, Sánchez J, Doebley J (2008) Population structure and genetic diversity of New World maize races assessed by DNA microsatellites. Am J Bot 95:1240-1253

Vigouroux Y, Mariac C, De Mita S, Pham JL, Gérard B, Kapran I, Sagnard F, Deu M, Chantereau J, Ali AY (2011) Selection for earlier flowering crop associated with climatic variations in the Sahel. PLoS ONE 6:e19563

Wellhausen E, Roberts J, Roberts LM, Hernandez X (1952) Races of maize in Mexico, their origin, characteristics, and distribution. The Bussey Institution, Harvard University, Cambridge

World Bank (2012) Turn down the heat: why a $4{ }^{\circ} \mathrm{C}$ warmer world must be avoided (a report for the World Bank by the Potsdam Institute for Climate Impact Research and Climate Analytics). The World Bank, Washington

Zeven AC (1998) Landraces: a review of definitions and classifications. Euphytica 104:127-139 